\title{
Environmental Differences between Two Neighboring Regions of Southern Spain
}

\author{
María-Dolores Huete-Morales ${ }^{1 *}$, José-Manuel Quesada-Rubio", \\ María-Jesús Rosales-Moreno², Esteban Navarrete-Álvarez ${ }^{2}$, \\ María-José Del-Moral-Ávila ${ }^{2}$ \\ ${ }^{1}$ Department of Statistics and Operational Research, Faculty of Labour Sciences, University of Granada, \\ C/Rector López Argüeta, s/n. Granada, Spain \\ ${ }^{2}$ Department of Statistic and Operational Research, Faculty of Sciences, University of Granada, \\ Campus de Fuente Nueva, s/n. Granada, Spain
}

Received: 27 June 2017

Accepted: 14 October 2017

\begin{abstract}
The aim of this paper is to identify the main factors that determine territorial differences between two large neighbouring provinces (Granada and Almería) that each occupy both sides of the Sierra Nevada mountain range in southern Spain. Our analysis produced a prediction model for riverside woodland cover, one of the variables that most strongly characterizes the differences between the two provinces. A general linear model was constructed for spatial analysis (spherical model with REML estimation), taking into account the location of the municipalities (longitude, latitude, and elevation) and other factors related to soil type, vegetation, or woodland cover. Interpolation of spatial data was performed by ordinary kriging. The predictions obtained over a grid of locations enabled patterns in each region to be derived and visualised, with very clear results. The pattern of riverside woodland cover is highly differentiated between the two provinces, despite their presenting adjoining areas.
\end{abstract}

Keywords: climate, neighbouring zones, ordinary kriging, spatial modelling, soil characteristics

\section{Introduction}

Significant differences in climate and land use between adjacent or neighbouring areas are relatively common and may have many causes, but geographic factors are especially important [1]. In studying these causes, we must compare the different variables that may interact to produce unique climates and ecosystems. Such variables include latitude, altitude, relief, sunshine,

*e-mail: mdhuete@ugr.es rainfall, humidity, temperature, and proximity to water bodies, and can produce a characteristic landscape. The rural abandonment, associated with demographic and economic changes also produce changes in the soil surface [2].

A natural region is an area bound by criteria of physical geography, mainly those related to relief, but also to climate, hydrography, vegetation, soil, and others [3]. Physical factors allow us to consider the natural region as a homogeneous and individual area. In Spain, the study of natural regions began in the mid20th century [4]. Orographic regions are determined by 
the predominant relief, phytogeographic regions by the plant formations present, and climatic regions by their latitude.

Climate is the set of events that characterise an area. To specify the climate of an area can require up to 30 years' study of atmospheric events, precipitation, and temperature, as well as atmospheric circulation, pressure, and other aspects. Although on a world scale and even within Europe, Andalusia is characterised as having a Mediterranean-type climate, the geographical factors of this area, such as the layout of the relief and the altimetry, create a climatic regionalisation with different bioclimatic zones. One such is the valley of the river Guadalquivir. This area is important not only for its considerable size, but because it presents some of the most characteristic features of the Mediterranean climate (high temperatures, irregular precipitation and strong insolation). In inland areas, the features of continentality are intensified. Moreover, the mountain areas of Andalusia are of great territorial significance, presenting lower temperatures due to the altitude and higher probabilities of precipitation and frost.

As we move inland and east, and also in the coastal mountains (which are not exposed to Atlantic winds), precipitation levels fall significantly and, therefore, aridity increases. The greater continentality and altitude of eastern Andalusia means that in areas such as Sierra Nevada, Cazorla, Segura, and Filabres, cooler average temperatures are recorded. The coastal zone is affected by the marine influence and enormously high levels of insolation (for example, the lower part of the Guadalquivir Valley receives more than 3,000 hours of sun per year). Within this area, Atlantic and Mediterranean slopes can be differentiated [5].

Another extreme of climatic diversity is the arid southeast, where the prevailing conditions (very high insolation and temperatures, very scant precipitation) make it a desert environment, with characteristics of Saharan flora and fauna [6].

Geostatistical modelling, the methodological approach adopted in this study, can be applied in many areas of land-type analysis. By performing a spatial study of land characteristics, taking into account relevant physical variables, we can achieve a spatial

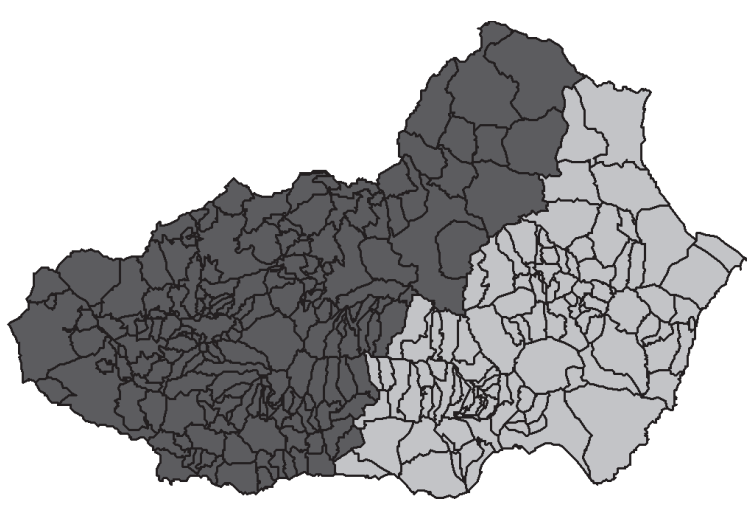

Fig. 1. Municipalities of Granada and Almería. differentiation that is very useful as a first step in territorial studies - especially when heterogeneous environmental characteristics may be present. Many research projects have made use of this technique. The literature in this area includes analyses of soil properties [7] or its contaminants [8] and territorial life cycle assessment, which is a methodological framework for the environmental assessment of territories [9].

\section{Material and Methods}

\section{Description of the Study Area}

The provinces of Granada and Almería (Fig. 1) are located in southeastern Spain, sheltered from the west by mountain ranges and exposed to a Mediterranean climate from the southeast. These provinces have surface areas of $12,635 \mathrm{~km}^{2}$ and $8,774 \mathrm{~km}^{2}$, respectively [10], and a joint population of 1.6 million inhabitants (919,319 and 700,000, respectively, according to the 2013 census) [11]. The boundaries of the two provinces were established as part of the national territorial reorganisation carried out in the mid-19th century, which sometimes produced strange shapes [12]. Thus, the province of Granada is elongated, for politicaleconomic reasons, and contains significant differences in its terrain. The province of Almería is somewhat more homogeneous in shape but has erosion problems [13-15]. Therefore, the study area presents a large topographic and climatic heterogeneity [16], not only across regions but within each region [17].

Each province is characterized by the presence of a large mountain range, the Sierra Nevada, which divides it transversely and gives rise to distinct microclimates, with Atlantic influence in the western part and a Mediterranean component in the eastern part [18]. However, this upland axis is not the only one, in either province, and other mountain ranges are to be found in both territories. The principal mountain range rises to altitudes of more than $3,000 \mathrm{~m}$ above sea level, and is accompanied by lesser ones that still rise above 2,000 $\mathrm{m}$ - a circumstance that distinguishes Granada/Almería from all other territories in the Iberian Peninsula.

The province of Granada is composed of three major areas: the coastal strip, separated from the rest by the Sierra Almijara and Sierra Nevada ranges; the sheltered inland area in the centre, where most of the population is concentrated; and the northeastern plateau, which is relatively arid and more sparsely populated. In recent years oak groves and grasslands have increased and, in contrast, olive groves, bare soils, and dry herbaceous crops have decreased [19]. Almería is more homogeneous, but two distinct areas can be distinguished: the southern part, bordering the coast and bounded to the north by the Sierra Nevada, and a lesspopulated sector in the northeast. In the coastal area, traditional crops have been substituted with intensive and extensive greenhouse crops under plastic, benefiting 
from the prevailing mild climate [20]. The area, called Las Alpujarras and which is shared between the two provinces, lies on the southern slopes of the Sierra Nevada massif and has a clear maritime influence. Accordingly, the climate is mild despite the high mean altitude. In the northern part of both provinces, population density is lower, the land is poorer, and annual temperatures more extreme. Precipitation is more abundant in NW, because the relief causes orographic rainfall by forcing masses of humid air to rise; when this air rises above the summits, it descends, its temperature increases again, and the air becomes dryer (the Föehm effect). Thus, the mountain barrier creates a division, isolating the different climatic regions [21-22].

The information supplied by the National Institute of Statistics and the Spanish Agency of Meteorology [23] from 1 January 1997 to 1 December 2012 show that the average number of hours of sunshine per month in Granada is 248.49 and 252.58 in Almería, although the smoothed series are fairly stable. The monthly average maximum temperature is $29.48^{\circ} \mathrm{C}$ in Granada and $28.73^{\circ} \mathrm{C}$ in Almería. The average monthly minimum temperature is $3.55^{\circ} \mathrm{C}$ in Granada, while it rises to $11.50^{\circ} \mathrm{C}$ in Almería. The monthly average humidity is $52.95 \%$ in Granada, while in Almería it is $59.53 \%$. The average number of clear days per month is 9.99 in Granada and 9.11 in Almería. The average number of cloud-covered days per month is 5.36 in Granada, while it is only 2.63 in Almería. The average monthly total rainfall is $37.87 \mathrm{ml}$ in Granada, while it is only $18.29 \mathrm{ml}$ in Almería. Fig. 2 shows the monthly rainfall in both provinces for this period. Therefore, despite the proximity of both areas, climatic differences are important.

\section{Theoretical/Analytical Framework}

Let $\mathrm{Y}$ the variable under study defined on $s_{i}, i: 1 \ldots N$, where $N$ denotes the available spatial divisions. In order to determine the spatial structure of the riverside woodland cover, this variable is taken as a response variable in a general linear model, which is going to be derived. The coordinates of $Y\left(s_{i}\right), i: 1 \ldots N$ where $s_{i}$ $=\left(x_{i}, y_{i}\right), i: 1 \ldots N$ represent the longitude and latitude of the centroids (central point) of the polygon for each

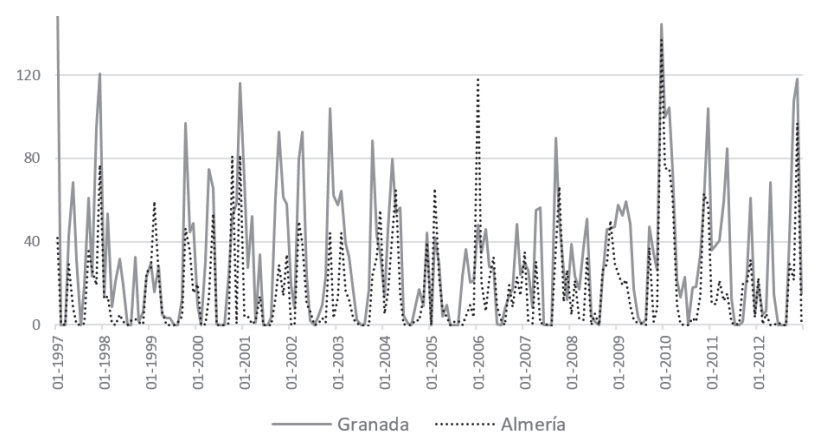

Fig. 2. Total monthly rainfall (mm) 1997-2012. municipality. This method takes into account variations that are spatially dependent in order to establish spatial dependence in terms of the distance between data locations. It is assumed that measurements of the variable of interest for areas in close proximity would have similar values, i.e., the correlation between pairs of variables in the process would depend on the distance between them.

Authors such as Noel Cressie and Peter Diggle first applied geostatistical spatial techniques assuming a single Gaussian response. However, geostatistical analysis has since been extended, with the application of classical and Bayesian approaches to distributions of discrete variables or to multivariate responses [24-26], thus expanding the study of geographically referenced data of all kinds; such extensions include classical geostatistical approaches such as studies by [27-30]. Diggle et al. [31] extended the analysis to non-Gaussian responses in a model that assumed an underlying Gaussian process.

The main aim of the present analysis (assuming a continuous Gaussian response) is to determine the statistical significance of the spatial structure of riverside woodland cover density using spatial modelling techniques including kriging prediction. The fundamental purpose of the latter is to obtain a mapped representation of the overall spatial distribution of this phenomenon, rather than that of obtaining concrete predictions for particular locations (since, in the case in question, this would only provide a very broad indication). Data consisting of locations $s_{i}$ and the observed property $Y_{i}$ can be represented by a model expressed as the result of two components, a mean term $\boldsymbol{\mu}\left(s_{i}\right)$ together with a certain additional variability (or error term) in the form $\boldsymbol{Y}\left(s_{i}\right)=\boldsymbol{\mu}\left(s_{i}\right)+\boldsymbol{\varepsilon}\left(s_{i}\right)$, where $\boldsymbol{\mu}\left(s_{i}\right)$ represents the overall (first-order) trend and where the error term $\varepsilon\left(s_{i}\right)$ describes the local (second-order) behaviour, described by a given covariance function [32]. The trend obtained may be constant $\boldsymbol{\mu}$ or nonconstant $\boldsymbol{\mu}(\boldsymbol{s})$. A more technical approach to stochastic processes can be found in Cox and Muller [33]. In this study, we opted for a non-constant trend because this approach provides better estimates. We now describe this technique with a non-constant trend.

The model may have a mean value that is dependent on the coordinates (or other external variables) and then the process is not stationary; therefore, it can be expressed as $\boldsymbol{Y}(\boldsymbol{s})=\boldsymbol{\mu}(\boldsymbol{s})+\boldsymbol{\varepsilon}(\boldsymbol{s})$ and its mean may be, for example, a polynomial function that depends on the coordinates of the locations (s). In this case, we wish to study the process error, which is defined as the difference between the variable and the trend, in order to describe the variability or structure of dependence around the average $\varepsilon(s)=\boldsymbol{Y}(\boldsymbol{s})-\boldsymbol{\mu}(\boldsymbol{s})$. In general, and unless the mean function of $\boldsymbol{Y}$ is constant, our interest in spatial structure analysis lies in the residuals.

Spatial correlation structures are usually represented by the variogram function instead of the covariance function or the correlation function. A more detailed 
description of the forms of correlation is given in [34-35]. The usual parameters that describe the variogram are the sill, range, or correlation and the nugget effect or purely random variation.

Given a set of spatially localized data $\boldsymbol{Y}\left(s_{i}\right)=Y_{i}$, $\boldsymbol{i}=\mathbf{1} \ldots \boldsymbol{N}$, the squared differences (Eq. 1) are termed empirical variogram ordinates, such that the behaviour of the expectations of the ordinates of the semivariogram is constant and equal to $\sigma^{2}$ if the correlation is zero, i.e., if there is no spatial correlation.

$$
\frac{1}{2}\left(Y\left(s_{i}\right)-Y\left(s_{j}\right)\right)^{2}, i, j=1 \ldots N
$$

In general, if correlation exists, it is expected to decrease with increasing distance between locations and will tend to disappear at large distances, such that the values of the expectations of the ordinates of the empirical semivariogram will tend toward $\sigma^{2}$ as the distance increases.

A graphic representation of the empirical variogram or of the correlation function corresponding to one or more models can help determine the goodness of fit of the model. The path of the empirical variogram points, its shape and its changes with distance will indicate the properties of the underlying process. The estimation of the variogram forms part of the analysis that can also be used to make predictions [36-37], although the reliability of the variograms obtained can be seriously affected by outliers or highly asymmetric distributions, and in such cases robust estimators of the variogram are recommended [38-39].

Two common approaches to fitting the model are to use unweighted or ordinary least squares (OLS) or the weighted least squares (WLS) criterion, either by numbers of pairs or by Cressie's method. Parameter estimation can also be performed by the maximumlikelihood (ML) or restricted maximum-likelihood (REML) procedure. The empirical variogram and the theoretical curve (the estimated parametric variogram) that gives the best fit can be shown together on a single graph. The theoretical form adopted (exponential, Gaussian, etc.) will approximately represent the trajectory of the points of the empirical variogram, assuming randomness. In the geostatistical context, references for this estimation method include [40-43].

\section{Interpolation with Kriging Techniques}

Knowledge of the parameters of the model is crucial to achieving one of the most important objectives in geostatistics, namely to make predictions for locations other than those observed for the phenomenon under study. Although our goal, given the nature of the information to be analyzed, is fundamentally that of description and exploration, we shall nevertheless make some predictions for the geographical area studied. In classical geostatistics, the kriging procedure is based on a knowledge of the variogram, while semivariances are used for the predictions. Kriging is a function of the data and of the correlation function or covariance, or of the variogram that characterizes the variability of the response variable being considered. Predictions in linear geostatistics are obtained as the sum of weighted data with kriging weights, dependent on the variogram, which vary depending on the strength of the spatial correlation and on the location of the point to be predicted with respect to the data sample. By obtaining predictions over a grid of locations, it is possible to graphically visualize the behaviour throughout the surface of the region.

\section{Data and Variables}

Since our objective is to determine whether there are differences in relation to riverside woodland cover (analysis variable, Y), the following factors that could
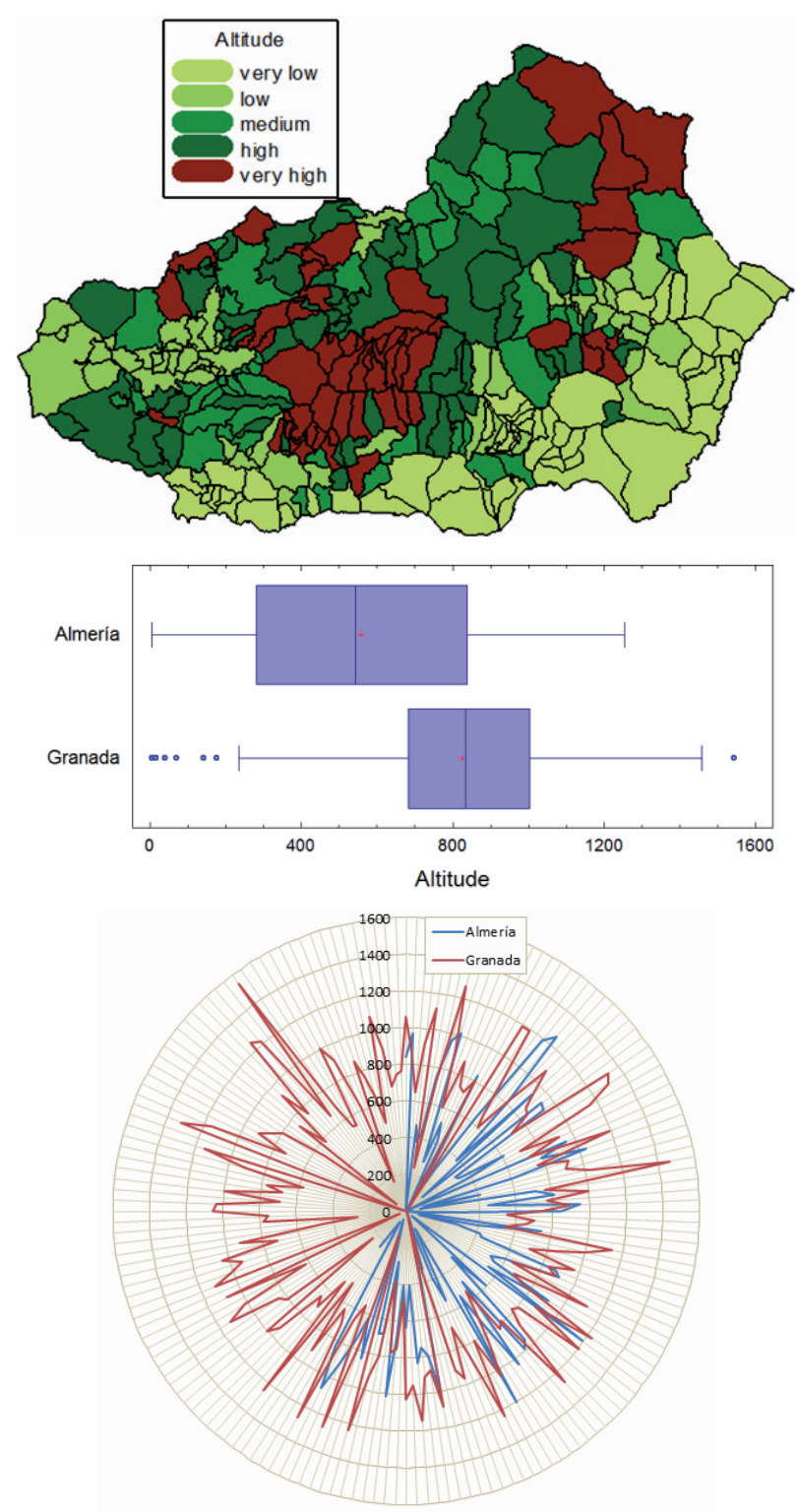

Fig. 3. Map, box-plot, and radar chart of altitudes in Granada and Almería by municipality. 
be closely related to this variable have been included in the model: total river surface (v1), riverside vegetal cover (v2), dense oak woodland cover (v3), dense conifer woodland cover (v4), dense eucalyptus woodland cover (v5), metamorphic rock (v6), sedimentary rock (v7), volcanic rock (v8), and intrusive rock (v9) [44]. In every case, the surface area is expressed as hectares/ $\mathrm{km}^{2}$ to enable comparability between municipalities of widely varying sizes. Following the guidelines in [45], we perform a geostatistical analysis with spatially referenced data. For this spatial analysis it is necessary to obtain maps or shapefiles for Spain [46] for the corresponding peninsular provinces, using the polygons and their centroids, with the ETRS89_30N system [47]. Geostatistical analysis was performed using R software [48].

\section{Results and Discussion}

\section{Descriptive Analysis}

Altitudes in Granada and Almería are analyzed by reference to the location of the town hall of each municipality. As shown in Fig. 3, in general those of Granada are at higher altitudes. The difference in altitude is particularly apparent in the southern part of each province (where mean altitudes are lower in both cases) - especially in Almería. The box plot reveals the presence of higher altitudes in Granada, albeit with some outliers (most of which reflect particularly low altitudes) than in Almería. The dispersion of the observations around the median altitude is lower in Granada than in Almería, but the data are reasonably symmetrical with respect to this median value in both provinces.

A spatial analysis is also performed of the following physical variables in the municipalities of both provinces (as hectares $/ \mathrm{km}^{2}$ ): in and around rivers and natural water courses (water surfaces, gallery forest, and other riverside vegetation); elsewhere - dense oak woodland; dense coniferous woodland; eucalyptus woodland; sedimentary rocks; metamorphic rocks; intrusive rocks; volcanic rocks. In cases for which data were missing, a linear model is constructed to predict these data, including as explanatory variables the altitude and centroid coordinates of each municipality.

With respect to the surface areas of rivers and natural streams (Fig. 4), the differences between the two provinces are evident as a prevalence of riverside vegetation in Almería, while gallery forests are mainly located in Granada. We also study the surface area of dense woodland per municipality (Fig. 4), and observe a predominance of oaks in Granada, conifers in Sierra Nevada (in both provinces) and eucalyptus in Almería. Regarding the types of rock to be found (Fig. 5), there is an almost total absence of intrusive and volcanic rocks (except two well-defined outcrops in the proximity of Sorbas and Cabo de Gata, respectively, both in Almería). Sedimentary rocks appear mostly in the northern part of Granada, and metamorphic rocks are more common in Granada than in Almería, mainly in areas with a high mean altitude.

\section{Interpolation of Spatial Data: Kriging}

In this analysis, the response variable is taken as the riverside woodland cover (Y) [49] and the explanatory variables are the spatial coordinate $(\boldsymbol{x}, \boldsymbol{y})$ and altitude $\boldsymbol{z}$
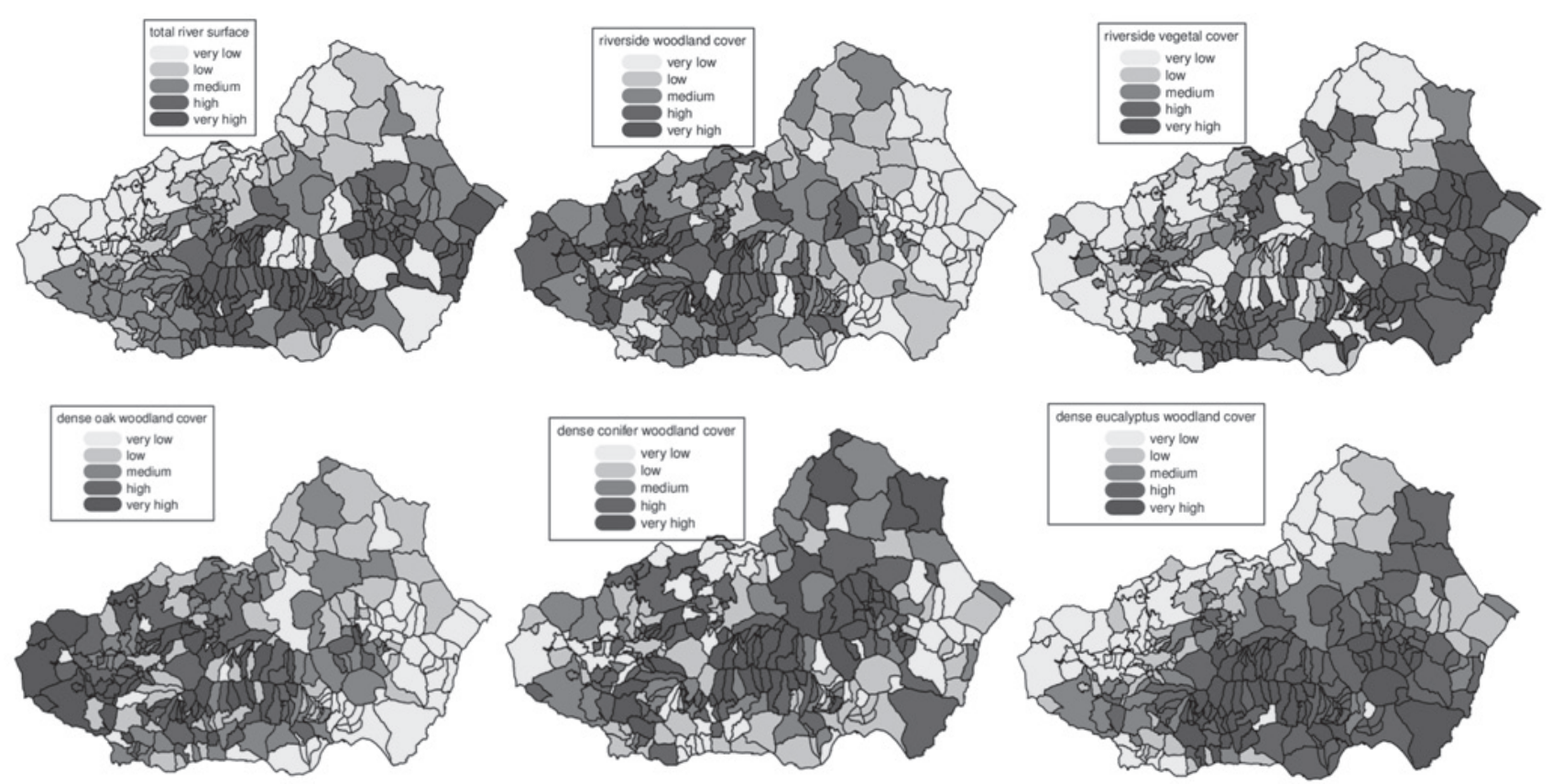

Fig. 4. Rivers, watercourses, and dense woodland in Granada and Almería by municipality: type of riverside vegetation. 

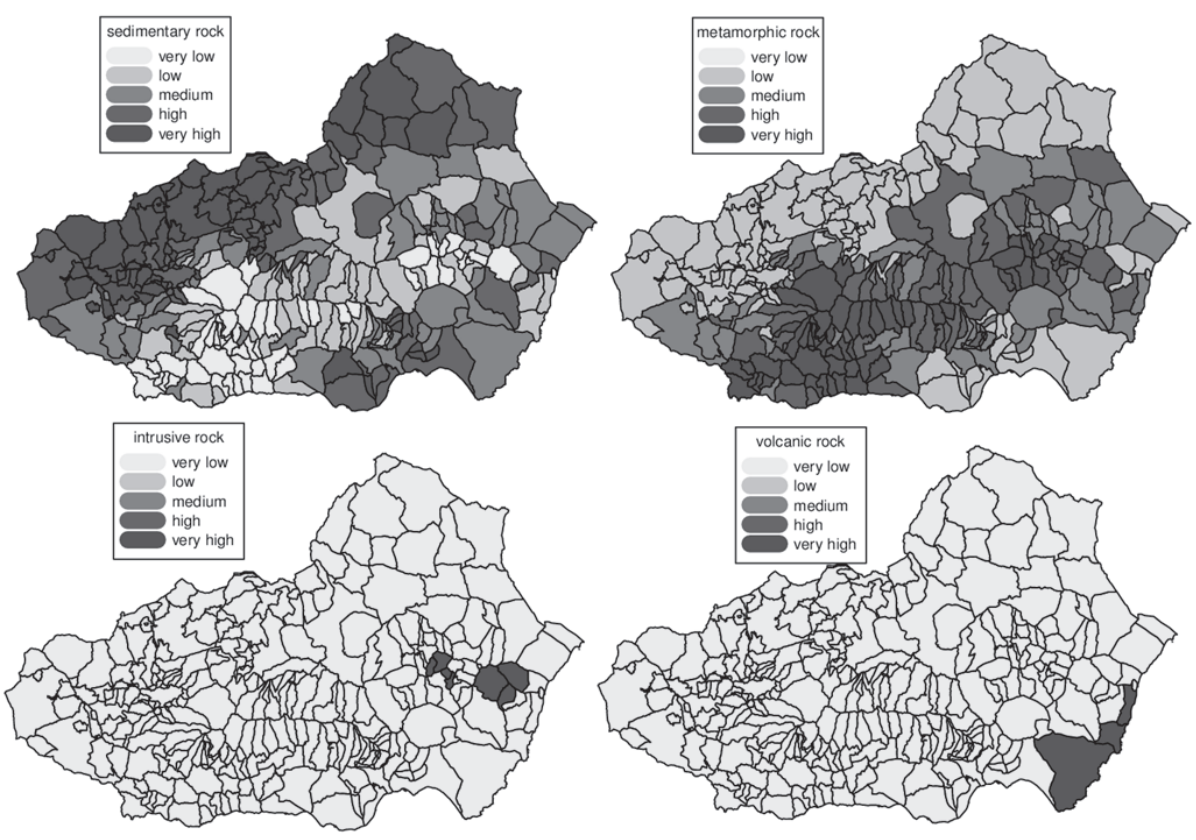

Fig. 5. Types of rock in Granada and Almería by municipality.

for each municipality. Other territorial measures are also considered as potential co-variables to fit the models $\left(\mathrm{v}_{1}\right.$ to $\left.\mathrm{v}_{9}\right)$. An exploratory analysis of the data collected for $\mathrm{Y}$ (hectares $/ \mathrm{km}^{2}$ ) shows that the data variability is considerable, with a significant number of outliers. A Box-Cox transformation [50] is performed to eliminate this variability $(\boldsymbol{\lambda}=\mathbf{0 . 2 7 9 5})$. The variables identified for possible inclusion in the model were transformed in the same way, thus eliminating excessive variability and the presence of outliers.

To eliminate the trend from the spatial information analyzed, and thus obtain a plausible constant trend hypothesis, the model is adjusted taking into account

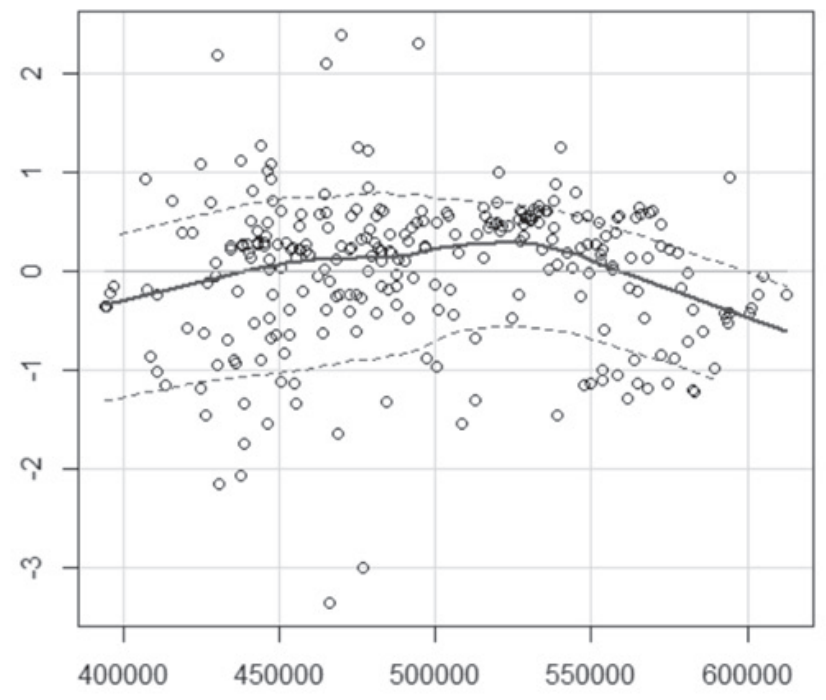

$\mathrm{x}$ the reference coordinates for each region $\boldsymbol{f}\left(s_{i}\right)$ and the significant covariables $\left(\mathrm{z}\right.$ and $\mathrm{v}_{1}$ to $\mathrm{v}_{9}$ ) included in the spatial model (Eq. 2), which are denoted as $Z\left(s_{i}\right)$ :

$$
\boldsymbol{Y}\left(s_{i}\right)=\boldsymbol{f}\left(s_{i}\right)+Z\left(s_{i}\right)+\boldsymbol{\varepsilon}
$$

The most suitable model thus obtained (adjusted R-squared $=0.5272 ;$ p-value $<0.0001)$ is shown in Table 1. This table shows that the measures altitude, latitude, and longitude are the most influential variables. Only the total river surface variable is significant in the model. This is congruent with the descriptive analysis of the monthly precipitations. If rainfall is more abundant,

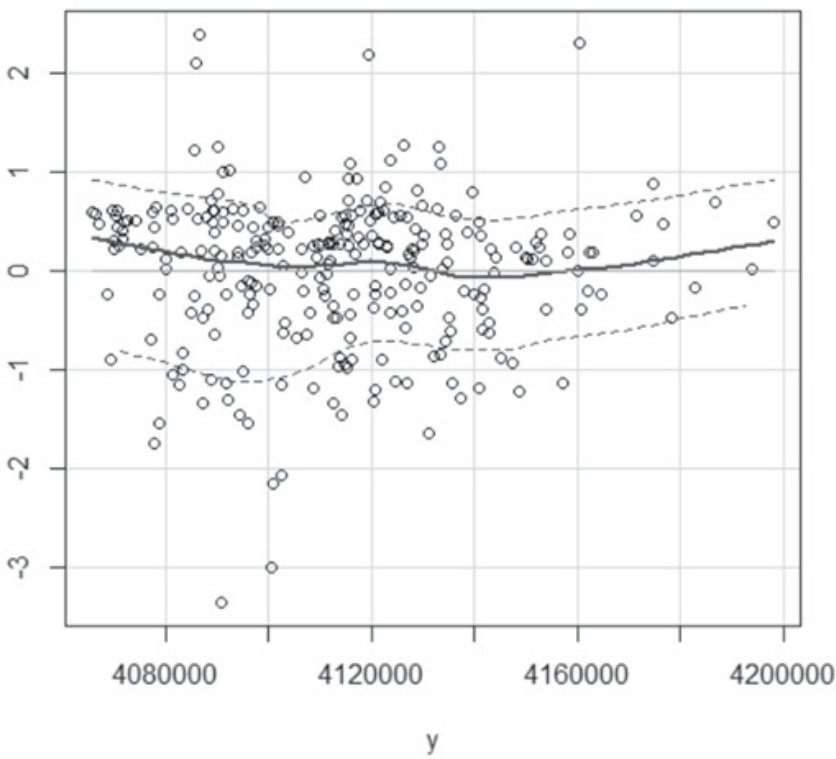

Fig. 6. Residuals of the model according to the $\mathrm{x}$ and $\mathrm{y}$ coordinates. 
Table 1. Model adjusted for the response variable.

\begin{tabular}{|c|c|c|}
\hline Coefficients & Estimate & $\mathrm{p}$-value \\
\hline Intercept & 40.0647 & 0.0002 \\
\hline Longitude $\mathrm{x}$ & -0.7118 & $<0.0001$ \\
\hline Latitude $\mathrm{y}$ & -1.2052 & $<0.0001$ \\
\hline Altitude $\mathrm{z}$ & 0.0016 & $<0.0001$ \\
\hline Total river surface $v_{1}$ & -0.1722 & 0.0940 \\
\hline
\end{tabular}

the river surfaces are higher and, therefore, riverside woodland cover is greater. The residuals present a normal behaviour pattern, and the scattergrams with respect to the geographical coordinates show that the trend has been successfully eliminated from the model (Fig. 6).

The best correlation function for the residuals $\boldsymbol{r}\left(s_{i}\right)=\boldsymbol{Y}\left(s_{i}\right)-\boldsymbol{\mu}\left(s_{i}\right)$ from the possible models (spherical, exponential, Gaussian, Matern, etc.) is selected using the experimental variogram. The following methods of parameter estimation are used: ordinary least squares (OLS), weighted least squares (WLS), Cressie's method, maximum-likelihood (ML) and restricted maximumlikelihood (REML). Of these, the best for our purposes is the spherical model with REML estimation, which presents the lowest degree of prediction error. The parameter values obtained are Beta $=-0.0249$, Tausq (nugget) $=0.4403$, Phi (range) $=34104.28$, SigmaSq $=0.1401$, and maximised log-likelihood $=-298.2$.

By obtaining predictions over a grid of locations, it is possible to graphically visualise the behaviour throughout the surface of the region. Fig. 7 shows the prediction of the study variable for a grid of 20,000 quadrants obtained from the estimated parameters of the model (ordinary kriging). This prediction map clearly shows two well-defined spaces from west to east and distinguishes very clearly the differences in the predictions for riverside woodland cover (hectares $/ \mathrm{km}^{2}$ )

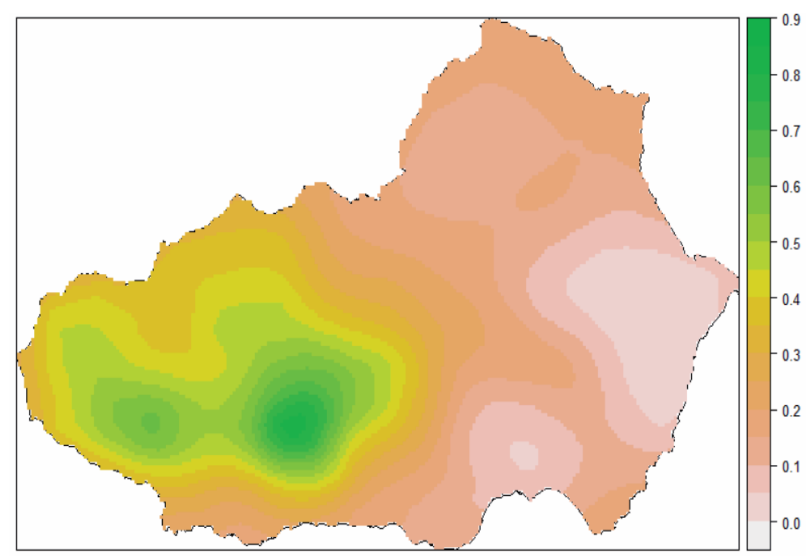

Fig. 7. Grid of points obtained by ordinary kriging; REML estimation and spherical model. of the two provinces. In SW Granada, the predictions are much higher $(0.40$ to 0.70$)$ than for Almería, which obtains values of around 0.10. Fig. 8 shows the contour map with the earlier predictions, on a 20000-quadrant grid, together with the variance of the predictions.

\section{Discussion}

Differences between the two provinces are significant with respect to minimum temperatures, humidity, rainfall, and cloudy days, while the other variables (sunshine hours, maximum temperatures, and sunny days) are not statistically relevant [51-52]. For this reason and despite its spatial proximity, the two regions have very different characteristics, accentuated by the Föehm effect. The peaks of Sierra Nevada cause humid air arriving from Guadalquivir Valley to rise, and when the humidity is high enough, rain will fall. When this mountain is left behind, the air temperature increases, humidity falls, and rainfall is scarce, thus creating the Tabernas Desert (in Almería) [53]. As a result, riverside vegetation is greater in Almería while gallery forests are more abundant in Granada.

In geostatistics, a great variety of models, methods, and techniques may be employed in the analysis, estimation, and visualisation of multivariate data, and many significant contributions have been made in this field [54]. The spatial prediction technique employed in this study can be used in various fields, including environmental science, making it possible to conduct spatial interpolations to the required degree of data detail, according to the grid considered. Many authors have applied such geostatistical techniques in areas such as soil analysis (for spatial sampling of soil [55] or in the analysis of soil properties [56-57]), in hydrogeology (to analyse groundwater constituents [58], considered as independent variables those related to location (altitude, latitude, longitude) and using universal kriging [59], and in climatology (for precipitation [60-61], temperature, or climate prediction [62]).

In this study, we highlight the differential features of two zones that, although geographically proximate, are very different. Future analyses will include other hydrological variables to improve the predictions obtained.

\section{Conclusions}

Our study highlights territorial differences between Granada and Almería, and the existence of significant climatic differences between these provinces. The relief of the terrain and, in particular, the orientation of the Penibetic System, as regards the incidence of sunlight and of prevailing winds, are of fundamental importance and must be taken into account in order to distinguish between the climates of the SE and NW faces of these mountain ranges. 

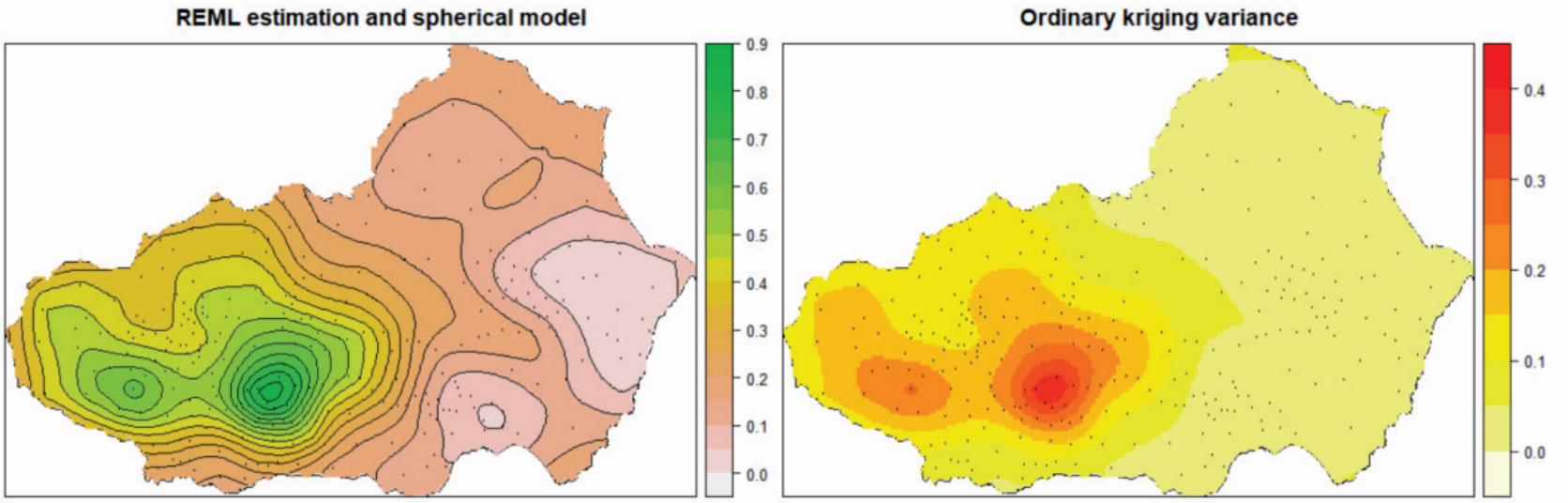

Fig. 8. Contour grid and prediction variance obtained by ordinary kriging.

Our spatial analysis confirms relevant territorial differences regarding the surface areas of rivers and natural streams and also in relation to the types of rock to be found. Taking into account relevant physical variables, the spatial study of land characteristics allows us to detect geospatial differentiation that is particularly useful in territorial studies when heterogeneous environmental characteristics may be present. Through interpolation of spatial data with ordinary kriging, we have derived a spherical model with WLS estimation which not only provides successful predictions over the selected grid of locations but also visualizes the behaviour throughout each region. Our study highlights the existence of significant differences in the predictions made using such a grid.

\section{Acknowledgements}

This work was supported by the Vice-Rector's Office for Political Science and Research-University of Granada through the project "Social-Labour Statistics and Demography" (30.BB.11.1101) at the Faculty of Labour Sciences.

\section{References}

1. ORTEGA M.T., MORALES C.G., LABAJO J.L. Contributions on changes in trends of climatic variables in the Spanish Central Plateau. Polígonos, 24, 43, 2013 [In Spanish] http://dx.doi. org/10.18002/pol.v0i24.841

2. MELENDEZ-PASTOR I., HERNÁNDEZ E.I., NAVARRO-PEDRENO J., GÓMEZ I. Socioeconomic factors influencing land cover changes in rural areas: the case of the Sierra de Albarracín (Spain). Applied Geography, 52, 34, 2014. http://dx.doi.org/10.1016/j. apgeog.2014.04.013

3. SOLÉ-SABARÍS L. Introduction. Spanish regions. In: Manuel de Terán, Luis Solé Sabarís y Juan Vilá Valentí. Regional Geography of Spain. Ed. Ariel: Barcelona, 1988 [In Spanish].
4. DANTÍN-CERECEDA J. Natural regions of Spain. CSIC, Inst. Juan Sebastián Elcano: Madrid, 1942 [In Spanish].

5. MERINO A., LÓPEZ A., HERMIDA L., SÁNCHEZ J.L., GARCÍA-ORTEGA E., GASCÓN E., FERNÁNDEZGONZÁLEZ S. Identification of drought phases in a 110year record from Western Mediterranean basin: Trends, anomalies and periodicity analysis for Iberian Peninsula. Global and Planetary Change, 133, 96, 2015. http://dx.doi. org/10.1016/j.gloplacha.2015.08.007

6. VILLALOBOS MEGÍA M. Geology of the Arid Zone of Almería, South East Spain. Regional Ministry of Environment: Andalusia, 2003.

7. CRUZ-CÁRDENAS G., LÓPEZ-MATA L., ORTIZSOLORIO C.A., VILLASEÑOR J.A., ORTIZ E., SILVA J.T., ESTRADA-GODOY F. Interpolation of Mexican soil properties at a scale of 1:1,000,000. Geoderma, 213, 29, 2014. https://doi.org/10.1016/j.geoderma.2013.07.014.

8. TARASOV D.A., MEDVEDEV A.N., SERGEEVA.P., SHICHKIN A.V., BUEVICH A.G. A Hybrid Method for Assessment of Soil Pollutants Spatial Distribution. AIP Conference Proceedings 1863, 050015, 2017. http://dx.doi. org $/ 10.1063 / 1.4992212$

9. LOISEAU E., ROUX P., JUNQUA G., MAUREL P., BELLON-MAUREL V. Implementation of an adapted LCA framework to environmental assessment of a territory: important learning points from a French Mediterranean case study. Journal of Cleaner Production, 80, 17, 2014. http://dx.doi.org/10.1016/j.jclepro.2014.05.059

10. LÓPEZ-ONTIVEROS A. Geography of Andalusia. Ariel: Barcelona, 2003 [In Spanish].

11. INE. Intercensal population estimates, 2013. Spanish National Institute of Statistics. Available online: http:// www.ine.es.

12. GÓMEZ-DÍAZ J. Territorial division of Spain. Provinces and judicial parties, 175 years. Toletum: Newsletter of the Royal Academy of Fine Arts and Historical Sciences of Toledo, 55, 151, 2014 [In Spanish].

13. FAULKNER H., RUÍZ J., ZUKOWSKYJ P., DOWNWARD S. Erosion risk associated with rapid and extensive agricultural clearances on dispersive materials in southeast Spain. Environmental Science \& Policy, 6, 115, 2003. http://dx.doi.org/10.1016/S1462-9011(02)00126-0

14. SANZ-DE-GALDEANO C., LOPEZ-GARRIDO A.C. The nevado-filabride complex in the western part of Sierra de los Filabres (Betic Internal Zone), structure and lithologic succession. Boletín geológico y minero, 127 (4), 823, 2016. 
15. SANZ-DE-GALDEANO C., LOPEZ-GARRIDO A.C. Transcurrent tectonics and melange in the Sierra Arana area (Betic Cordillera, NE of Granada). Estudios geológicos, 72 (2), e055, 2016.

16. GARCÍA-LLORENTE M., MARTÍN-LÓPEZ B., NUNES P.A., CASTRO A.J., MONTES C. A choice experiment study for land-use scenarios in semi-arid watershed environments. Journal of Arid Environments, 87, 219, 2012. http://dx.doi.org/10.1016/j.jaridenv.2012.07.015

17. KIM J. Crossing-over between land cover and land use: Exploring spatially varying relationships in two large US metropolitan areas. Applied Geography, 60, 37, 2015. http://dx.doi.org/10.1016/j.apgeog.2015.03.002

18. OLIVA M., MORENO I. Sierra Nevada, nexus between two teleconnection patterns: Nao and Wemo. In Regional Climate Change and its Impacts, series A, 6, 199, Spanish Climatology Association, Tarragona, Spain, 2008 [In Spanish].

19. RODRIGUEZ-GALIANO V., CHICA-OLMO M. Land cover change analysis of a Mediterranean area in Spain using different sources of data: Multi-seasonal Landsat images, land surface temperature, digital terrain models and texture. Applied Geography, 35, 208, 2012. http:// dx.doi.org/10.1016/j.apgeog.2012.06.014

20. MUÑOZ-ROJAS M., DE LA ROSA D., ZAVALA,L.M., JORDÁN A., ANAYA-ROMERO M. Changes in land cover and vegetation carbon stocks in Andalusia, Southern Spain (1956-2007). Science of the Total Environment, 409, 2796, 2011. http://dx.doi.org/10.1016/j.scitotenv.2011.04.009

21. BERGHAENEL R.P. Föehm effect in the Catalan Pyrenees: general characteristics and a case study. Time and climate, 5 (10), 2014 [In Spanish].

22. PASCUAL R., CALLADO A. Mountain accidents associated with northern flows in the Mediterranean Pyrenees. Tethis, 7, 41, 2010.

23. INE. Statistical Yearbook of Spain: AEMET (Spanish State Meteorological Agency), 2013. Spanish National Institute of Statistics. Available online: http://www.ine.es.

24. WACKERNAGEL H. Multivariate geostatistics. 3rd Edition. Springer: Berlin, 2003.

25. SCHABENBERGER O., GOTWAY C.A. Statistical Methods for Spatial Data Analysis. Chapman \& Hall/CRC Press: United State, 2005.

26. GAETAN C., GUYON X. Spatial statistics and modeling. Springer: New York, 2010.

27. JOURNEL A., HUIJBREGTS C. Mining Geostatistics, Academic Press: London, 1978.

28. ISAAKS E., SRISVASTAVA R. An Introduction to Applied Geostatistics, Oxford University Press: New York, 1989.

29. JOURNEL A. Fundamentals of geostatistics in five lessons. American Geophysical Union: Florida, 1989. http://dx.doi. org/10.1029/SC008

30. GOOVAERTS P. Geostatistics for Natural Resources Evaluation, Oxford University Press: New York, 1997.

31. DIGGLE P.J., TAWN J.A., MOYEED R.A. Model based geostatistics (with discussion). Applied Statistics, 47, 299, 1998. http://dx.doi.org/10.1111/1467-9876.00113

32. CRESSIE N. Statistics for Spatial Data, Wiley \& Sons: New York, 2015.

33. COX D.R., MULLER H.D. The Theory of Stochastic Processes, Methuen: London, 1965.

34. SCHLATHER M. Introduction to positive definite functions and to unconditional simulation of random fields, Technical Report ST-99-10, 1999. Dept. Maths and Stats, Lancaster University, Lancaster, UK.
35. OLIVER M. The variogram and kriging. In Handbook of Applied Spatial Analysis. Springer-Verlag: Berlin, 2010. http://dx.doi.org/10.1007/978-3-642-03647-7_17.

36. DIGGLE P., MENEZES R., SU T. Geostatistical inference under preferential sampling. Journal of the Royal Statistical Society: Series C, 59 (2), 1912, 2010.

37. ZIMMERMAN D., ZIMMERMAN M. A comparison of spatial semivariogram estimators and corresponding kriging predictors, Technometrics, 33, 77, 1991. http:// dx.doi.org/10.1080/00401706.1991.10484771

38. CRESSIE N. Fitting variogram models by weighted least squares, Journal of the International Association of Mathematical Geology, 17, 563, 1985. http://dx.doi. org/10.1007/BF01032109

39. MARCHANT B.P., LARK R.M. Robust estimation of the variogram by residual maximum likelihood. Geoderma, 140, 62, 2007.

40. PARDO-IGÚZQUIZA E. MLREML: a computer program for the inference of spatial covariance parameters by maximum likelihood and restricted maximum likelihood, Computers and Geosciences, 23, 153, 1997. http://dx.doi. org/10.1016/S0098-3004(97)85438-6

41. WEBSTER R., WELHAM S.J., POTTS J.M., OLIVER M.A. Estimating the spatial scale of regionalized variables by nested sampling, hierarchical analysis of variance and residual maximum likelihood. Computers and Geosciences, 32, 1320, 2006. http://dx.doi.org/10.1016/j. cageo.2005.12.002

42. HAINING R., KERRY R., OLIVER M. Geography, Spatial Data Analysis, and Geostatistics: An Overview. Geographical Analysis, 42 (1), 7, 2010. http://dx.doi. org/10.1111/j.1538-4632.2009.00780.x

43. DESASSIS N., RENARD D. Automatic variogram modeling by iterative least squares: univariate and multivariate cases. Mathematical Geosciences, 45, 453, 2013. http://dx.doi.org/10.1007/s11004-012-9434-1

44. SIMA: System of Multiterritorial Information of Andalusia, 2009. Institute of Statistics and Cartography of Andalusia. Available online: http://www.juntadeandalucia. es/institutodeestadisticaycartografia/sima/index 2.htm

45. HUETE-MORALES M.D., QUESADA-RUBIO J.M., NAVARRETE-ÁLVAREZ E., ROSALES-MORENO M.J., DEL-MORAL-ÁVILA M.J. Geostatistical analysis of the causes of environmental noise in Spain. Environmental Engineering and Management Journal, 13 (10), 1535, 2014.

46. DICES. Cartographic directory of Spain, 2013 [In Spanish]. Available online: http://www.dices.net/poblaciones/4292. html.

47. ESRI. Map Service, 2013. Available online: http://www. arcgis.com/home/gallery.html.

48. R-PROJECT. The R-project for statistical computing, 2013. Available online: http://www.r-project.org/.

49. IVITS E., CHERLET M., MEHL W., SOMMER S. Estimating the ecological status and change of riparian zones in Andalusia assessed by multi-temporal AVHHR datasets. Ecological Indicators, 9, 422-431, 2009. http:// dx.doi.org/10.1016/j.ecolind.2008.05.013

50. BOX G.E.P., COX D.R. An analysis of transformations. Journal of the Royal Statistical Society, Series B, 26, 211, 1964.

51. GARCÍA-BARRÓN L., AGUILERA M, SOUSA A. Evolution of annual rainfall irregularity in the southwest of the Iberian Peninsula. Theoretical and Applied Climatology, 103 (1), 13, 2011. 
52. PEÑA-GALLARDO M., GÁMIZ-FORTIS S.R., CASTRO-DÍEZ Y., ESTEBAN-PARRA M.J. Comparative analysis of drought indices in Andalusia 1901-2012. Geographical Research Notebooks, 42 (1), 67, 2016 [In Spanish].

53. MENDOZA-FERNÁNDEZ A., PÉREZ-GARCÍA F., MARTÍNEZ-HERNÁNDEZ F., MEDINA-CAZORLA J., GARRIDO-BECERRA J., MERLO M., GUIRADO J., MOTA J. Threatened plants of arid ecosystems in the Mediterranean Basin: A case study of the south-eastern Iberian Peninsula. Oryx, 48 (4), 548, 2014. http://dx.doi. org $/ 10.1017 / \mathrm{S} 0030605313000495$

54. CHILES J.P., DELFINER P. Geostatistics: modelling spatial uncertainty, John Wiley \& Sons, Inc.: New York, 2009.

55. LARK R.M. Optimized spatial sampling of soil for estimation of the variogram by maximum likelihood. Geoderma, 105 (1-2), 49, 2002.

56. MARCHANT B.P., SABY N., LARK R., BELLAMY P, JOLIVET C., ARROUAYS D. Robust analysis of soil properties at the national scale: cadmium content of French soils. European Journal of Soil Science, 61, 144, 2010. http://dx.doi.org/10.1111/j.1365-2389.2009.01212.x

57. DIODATO N., CECCARELLI M. Multivariate indicator Kriging approach using a GIS to classify soil degradation for Mediterranean agricultural lands. Ecological Indicators, 4 (3), 177-187, 2004. http://dx.doi.org/10.1016/j. ecolind.2004.03.002.

58. PARDO-IGUZQUIZA E., CHICA-OLMO M., GARCIASOLDADO M.J., LUQUE-ESPINAR J.A. Using Semivariogram Parameter Uncertainty in Hydrogeological Applications, Ground Water, 47 (1), 25, 2009. http://dx.doi. org/10.1111/j.1745-6584.2008.00494.x

59. ANDERSON F. Multivariate Geostatistical Model for Groundwater Constituents in Texas. International Journal of Geosciences, 5 (13), 1609, 2014. http://dx.doi. org/10.4236/ijg.2014.513132

60. AMRI N., JEMAIN A., HASSAN W. Ordinary kriging base on OLS-WLS fitting semivariogram: Case of gold vein precipitation. In AIP Conference Proceedings. AIP, 1039, 2014.

61. FAWCETT L., WALSHAW D. Estimating the probability of simultaneous rainfall extremes within a region: a spatial approach. Journal of Applied Statistics, 41 (5), 959, 2014. http://dx.doi.org/10.1080/02664763.2013.856872

62. AROWOLO A., BHOWMIK A., QI W., DENG X. Comparison of spatial interpolation techniques to generate high-resolution climate surfaces for Nigeria. International Journal of Climatology, 2017. http://dx.doi.org/10.1002/ joc.4990 [published online] 